\title{
O PIBID NA FORMAÇÃO INICIAL E INSERÇÃO À DOCÊNCIA DA EDUCAÇÃO B ÁS ICA
}

\author{
Elizabeth Raimann \\ Juliana Alves da Guarda
}

RESUMO: Este artigo, resultado de pesquisa apoiada pela Capes, problematizou o Programa Institucional de Bolsa de Iniciação à Docência (Pibid) dos cursos de licenciatura em Biologia, Física, Matemática e Química da Universidade Federal de Goiás, Regional Jataí. Objetivou-se compreender a contribuição do programa para a permanência na licenciatura e na formação inicial, levando, posteriormente, a atuar na educação básica. A investigação qualitativa pautou-se em questionário encaminhado a 97 egressos dos cursos de licenciatura pelo sistema Google-Drive, tendo a análise crítica de conteúdo nas contribuições de Duarte (2010), Freitas (2007) e Vieira (2017). A racionalidade técnica ficou evidente nos subprojetos desenvolvidos em detrimento da práxis. Dos egressos, doze afirmaram que o programa contribuiu na formação inicial permitindo conhecer a realidade escolar, a se identificar ou não pela licenciatura escolhida; as bolsas foram fundamentais para a permanência nos cursos, mas apenas cinco deles estão atuando na educação básica.

PALAVRAS-CHAVE: Formação inicial de professores. Programa Institucional de Bolsa de Iniciação à Docência. Docência na educação básica.

\section{INTRODUÇão}

O presente artigo apresenta os resultados de pesquisa desenvolvida durante o mestrado no Programa de Pós-graduação em Educação, na Regional Jataí da Universidade Federal de Goiás $(\mathrm{UFG} / \mathrm{REJ})^{1}$, hoje Universidade Federal de Jataí. O tema central da pesquisa foi o Programa Institucional de Bolsa de Iniciação à Docência (Pibid) na Educação Básica implementado na UFG/REJ.

Este programa, financiado pela Coordenação de Aperfeiçoamento de Pessoal de Nível Superior (Capes), teve seu início em 2007, tendo por objetivo aprimorar a formação inicial e continuada de professores da educação básica. O intuito era, inicialmente, atender a falta de professores nas licenciaturas em Biologia, Física, Química e Matemática.

Para cumprir com o seu propósito, ofereceu bolsas de iniciação à docência aos envolvidos, sendo eles, os discentes selecionados do curso de licenciatura, o professor supervisor da educação básica e o professor orientador do ensino superior. Com esse incentivo financeiro buscava valorizar o magistério, contribuindo com o desempenho dos alunos nas escolas de educação básica, inserindo o licenciando no contexto escolar e oportunizando experiências metodológicas inovadoras, a fim de que este vivenciasse a realidade escolar e buscasse soluções para os problemas encontrados na prática pedagógica, tendo como apoio os professores supervisores tanto da educação básica quanto da universidade na qual estava vinculado.

Naquele momento, a UFG participou do primeiro edital com um projeto institucional, no qual estavam vinculados subprojetos das licenciaturas de Ciências Biológicas, Física, Matemática e Química. A Regional de Jataí, por sua vez, contribuiu submetendo um subprojeto na área da licenciatura em Matemática. As licenciaturas de Ciências Biológicas, Física e Química se inseriram ao Pibid a partir de 2011. Nesse mesmo período, na UFG, outras áreas das licenciaturas foram contempladas atendendo as demandas dos campi de Goiânia, Catalão, Cidade de Goiás e Jataí (GUARDA, 2019).

1 Em 2020 a Regional Jataí efetivamente se desvinculou da UFG, conforme Lei $\mathrm{n} .{ }^{\circ} 13.635 / 2018$, tornando-se Universidade Federal de Jataí (UFJ) com seu reitor pró-tempore em exercício (BRASIL, 2018). 
Buscando compreender a função do Pibid que se propõe incentivar a permanência dos alunos na licenciatura e levá-los a atuar na educação básica após a conclusão do curso, a pesquisa levantou o seguinte questionamento: O Pibid contribuiu na formação inicial dos egressos dos cursos de licenciatura em Biologia, Física, Química e Matemática, da Universidade Federal de Goiás, Regional Jataí, levando-os a atuar, posteriormente na educação básica?

A escolha em pesquisar estas licenciaturas se deu pelos investimentos do governo federal ao programa nessas áreas pela falta de profissionais para atuar na educação básica. Assim, mediante a pesquisa de campo, com um questionário enviado pelo sistema Google Drive, buscou-se conhecer os egressos desses cursos, a contribuição do programa para a sua formação e, por fim, se estavam atuando na educação básica. A pesquisa teve o aval do comitê de ética, mediante o processo CAAE n. ${ }^{\circ}$ 70503517.4.0000.5083. As contribuições dos respondentes foram analisadas a partir do referencial crítico tendo como metodologia a análise de conteúdo.

$\mathrm{O}$ artigo apresenta inicialmente a metodologia da pesquisa e na sequência os resultados e a sua discussão. Ao final, algumas considerações acerca do programa e suas contradições enquanto uma política de formação inicial de professores.

\section{Os CAMinhos da PESQuisa}

A pesquisa com egressos dos cursos de licenciatura em Ciências Biológicas, Física, Química e Matemática da UFG, Regional Jataí, foi realizada entre os anos de 2017 e 2018. Após o projeto de investigação passar pelos trâmites do Comitê de Ética, buscou-se na secretaria do Pibid da UFG/Regional Jataí os nomes e e-mail dos egressos participantes do programa entre 2009 a 2016. Desse levantamento, localizaram-se 99 egressos, sendo caminhados 97 e-mails. No corpo do e-mail, inicialmente, apresentou-se ao egresso o objetivo da pesquisa e a opção se desejava ou não participar dela, em caixa de diálogo na parte anterior ao questionário, garantindo o sigilo das informações pessoais, segundo o Termo de Consentimento Livre e Esclarecido (TCLE). Encaminhou-se, como instrumento de coleta de dados, um questionário semiestruturado com 19 questões, mediante o sistema Google-Drive.

Realizaram-se quatro tentativas de envio dos questionários aos 97 egressos e, ao final, apenas doze deram a devolutiva de suas respostas. A pouca adesão à pesquisa levou a considerar que, dentre as possíveis dificuldades, estaria a possibilidade de que os contatados poderiam estar receosos em responder, tendo em vista que, naquele momento específico da consulta, a Capes havia encaminhado um e-mail ${ }^{2}$ aos pibidianos solicitando dados de sua participação no programa e da sua atuação na educação básica. Isso levou a inferir que estes egressos poderiam estar constrangidos uma vez que, no momento da adesão ao programa, o bolsista assinava uma declaração junto à coordenação geral, conforme Portaria $n^{\circ} 38$, de 12 de dezembro de 2007, sobre os deveres dos bolsistas de iniciação à docência se comprometendo ao assinar a declarar na concessão da bolsa, o seu interesse em atuar na docência após concluir a licenciatura no ensino superior. Nesse contexto, com declaração assinada, os egressos poderiam ter entendido que se não estiverem atuando, isso traria algum transtorno, pois as licenciaturas escolhidas faziam parte dos primeiros cursos contemplados com a bolsa do programa, enquadrando-se nessa portaria.

2 Em 06/08/2018, o Tribunal de Contas da União, levantamento formacao@tcu.gov.br, solicitou informações em pesquisa com alunos beneficiários do Programa, para conhecer melhor o perfil dos estudantes e colher opinião sobre o quanto esse programa auxiliou em sua formação. 
Das devolutivas, analisou-se o conteúdo dos doze respondentes, sendo elas agrupadas da seguinte forma: no primeiro grupo a caracterização dos egressos; no segundo as contribuições do programa na formação inicial do egresso e no terceiro sua atuação na educação básica, após a conclusão do curso. Os respondentes foram nomeados considerando a primeira letra dos cursos de licenciatura: (Ciências Biológicas) B1 B2, B3; (Física) F1, F2, F3; (Matemática) M1, M2, M3, M4; (Química) Q1, Q2.

\section{O Pibid e A SUA IMportânCIA Na FORMAÇão inicial de licenciandos}

O Pibid foi elaborado com o propósito de incentivar a licenciatura mediante a formação inicial de docentes e objetivava desenvolver ações pedagógicas na escola da educação básica em parceria com a universidade, a fim de contribuir na formação dos envolvidos, graduandos e professores da rede, além de colaborar com o Índice de Desenvolvimento da Educação Básica (Ideb).

A formação inicial de professores deve ser analisada no bojo das condições subjetivas do trabalho docente que, por sua vez, junto às condições objetivas implicam na profissionalização destes profissionais da educação. Isso envolve ações concretas como o piso salarial, plano de carreira, condições de trabalho com jornadas dignas, além de formação inicial com uma base teórica e prática sólida, e uma formação continuada que atenda à demanda pela necessidade de os profissionais da educação estarem atualizados.

Basso (1988), ao tratar da autonomia e controle do trabalho docente, pondera sobre a especificidade deste trabalho que se realiza com seres humanos afirmando que o elemento da autonomia está presente de forma relativa. Porém, o controle sobre o trabalho do professor, ocorre em outra dimensão, a partir da sua formação inicial, mediante uma "formação aligeirada [...] por falta de conhecimentos mais profundos sobre conteúdos e metodologias, vê-se obrigado a reproduzir o conteúdo do livro didático" (BASSO, 1998, p. 23). Nesse aspecto, o professor se tornaria refém de uma educação reprodutivista, acrítica e individualista, tendo, desse modo, relativa autonomia.

As reformas educacionais que vêm sendo executadas nas últimas décadas pautam-se em uma visão gerencialista da educação. Objetivam uma formação de caráter técnico, aligeirado, sob o pretexto de que o currículo contempla mais a teoria do que a prática profissional. Sob essa lógica, as reformas curriculares para os cursos de formação inicial de professores da educação básica, dão espaço para um desenvolvimento basicamente técnico, acrítico, despolitizado e desintelectualizado, na análise de Duarte (2010) voltado para o aprender a aprender, subsidiado pela epistemologia da prática.

Nesse contexto, existe uma disputa entre dois projetos de formação inicial de professores. Uma formação defendida por educadores e suas entidades representativas, que lutam pela valorização e profissionalização docente, caracterizada por uma formação humana, técnica e política, embasada na práxis, voltada à cidadania. E outro projeto, defendido por empresários da educação, que busca uma formação de professores embasada na preparação técnica, aligeirada e fragmentada, dando lugar a um processo de desqualificação, desprofissionalização e desvalorização do trabalho docente. Desta forma, contrariando as reivindicações da luta dos educadores e suas entidades por uma formação consistente, desde a década de 1980. 
Nesse sentido, o trabalho docente, condições objetivas e subjetivas, é um campo de disputa, de contradições, e é nesse contexto que se deve analisar a proposta do Pibid na formação inicial de professores.

Os fundamentos legais do Pibid estão presentes na LDB, Lei no 9.394/1996, artigo 62 do capítulo VI que trata dos profissionais da educação, alterado posteriormente, pela Lei $\mathrm{n}^{\circ} 12.796$, de 4 de abril de 2013, que dá nova redação a esse artigo no seu inciso 5, como se lê:

\begin{abstract}
A União, o Distrito Federal, os Estados e os Municípios incentivarão a formação de profissionais do magistério para atuar na educação básica pública mediante programa institucional de bolsa de iniciação à docência a estudantes matriculados em cursos de licenciatura, de graduação plena, nas instituições de educação superior (BRASIL, 2013b, art.62, p. 3).
\end{abstract}

Para a legislação educacional, os cursos de licenciatura são responsáveis pela formação de professores, para atuar na educação básica, formação essa que acontece em dois momentos, a formação inicial e a continuada. Com a nova redação do artigo 62 da LDB, o Pibid seria um estímulo à formação de professores para atuarem na educação básica pública ofertados para cursos de licenciatura nas Instituições de Ensino Superior, independente de elas serem públicas ou privadas. Dados dão conta que a partir de 2013 o Pibid se expandiu para além da esfera pública. Significa que a esfera federal correspondia a 35\%, a estadual $13 \%$ e a municipal $6 \%$, totalizando $54 \%$ na categoria administrativa pública. Em relação às instituições privadas com fins lucrativos correspondia a 39\%, enquanto que as sem fins lucrativos chegavam a 7\%, o percentual total das instituições na categoria privada equivale a 46\% (GUARDA, 2019).

No trajeto de mudanças da LDB, em 2007, com a elaboração do Plano de Desenvolvimento da Educação (PDE), o Pibid aparece como programa instituído pela Capes a fim de incentivar a formação inicial do professor, bem como valorizar o magistério (BRASIL, 2007). Com o PDE diversos programas são formulados para atenderem à educação básica e ao ensino superior, na busca da melhoria da qualidade da educação, além da proposta do Índice de Desenvolvimento da Educação Básica (Ideb), aferindo o desempenho dos alunos nas avaliações internas e externas.

Diante do PDE e da Capes como responsável em coordenar a formação de professores, em 29 de janeiro de 2009, foi aprovado o Decreto $n^{\circ} 6.755$, que dispõe sobre a Política Nacional de Formação de Profissionais do Magistério da Educação Básica. Nesse Decreto foram estabelecidos os princípios desta política, afirmando o compromisso do Estado com a formação de professores para todas as etapas da educação básica e também o comprometimento com uma educação de qualidade, para todas as crianças, jovens e adultos (BRASIL, 2009).

Esse documento apresentava alguns princípios para a formação docente, dos quais se destacam: formação de professores como compromisso público de Estado; colaboração dos entes federados com a formação; garantia de uma formação de qualidade nas instituições de ensino presencial e à distância; articulação entre teoria e prática nos cursos de formação; a importância da escola como espaço necessário para formação inicial e continuada de professores; importância de ter nas instituições de ensino superior um projeto formativo para refletir a formação docente; consideração da formação continuada como componente principal da profissionalização docente e a importância de diferentes saberes e da experiência do professor no contexto escolar (BRASIL, 2009). 
Observando os objetivos apresentados pelo Decreto acima para a formação de professores, destacam-se: proporcionar a melhoria da qualidade da educação pública; ofertar a expansão dos cursos de formação inicial e continuada nas universidades de ensino superior; valorizar o docente por meio da formação inicial e continuada, promover uma formação teórico-metodológica entre outros (BRASIL, 2009).

Diante dessa política nacional de formação de professores para a educação básica o Pibid passou a ter importância no contexto dos cursos de licenciatura, em específico daqueles com poucos professores formados diante da demanda por docentes nas áreas das exatas e biológicas para a educação básica. Por outro lado, ao objetivar aproximar a universidade da educação básica na tentativa de melhorar, tanto a qualidade da formação de professores quanto a educação seguem a pedagogia dos resultados, tendo metas e índices a alcançar.

Posto isso, a pesquisa junto aos egressos das licenciaturas de Ciências Biológicas, Física, Matemática e Química da UFG/Regional Jataí (UFG/REJ) teve a sua relevância, buscando conhecer as contribuições do Pibid para a formação inicial, bem como a inserção e atuação na educação básica, após a conclusão do curso.

Considerando o perfil dos respondentes, os dados foram sistematizados no quadro abaixo.

Quadro 1 - Perfil dos egressos do Pibid UFG/REJ entre 2009 e 2016

\begin{tabular}{|c|c|c|c|}
\hline Egressos & Subprojeto & $\begin{array}{c}\text { Idade dos egressos do } \\
\text { Pibid }\end{array}$ & $\begin{array}{c}\text { Tempo de permanência no } \\
\text { Pibid }\end{array}$ \\
\hline B1 & Biologia & 20 a $25 \operatorname{anos}$ & 2 anos ou mais \\
\hline B2 & Biologia & 26 a 30 anos & 1 ano e meio \\
\hline B3 & Biologia & 26 a 30 anos & 1 ano e meio \\
\hline F1 & Física & 20 a 25 anos & 1 ano \\
\hline F2 & Física & 20 a 25 anos & 2 anos ou mais \\
\hline F3 & Física & 20 a 25 anos & 1 ano \\
\hline M1 & Matemática & 26 a 30 anos & 2 anos ou mais \\
\hline M2 & Matemática & 26 a 30 anos & 2 anos ou mais \\
\hline M3 & Matemática & 20 a 25 anos & 2 anos ou mais \\
\hline M4 & Matemática & 20 a 25 anos & 1 ano e meio \\
\hline Q1 & Química & 26 a 30 anos & 2 anos ou mais \\
\hline Q2 & Química & 26 a 30 anos & 2 anos ou mais \\
\hline
\end{tabular}

Fonte: Guarda (2019, p. 98).

Dos 12 respondentes, têm-se seis egressos com a idade entre 20 e 25 anos e os outros seis entre 26 e 30 anos. Pode se considerar que todos são jovens e estão dispostos a ingressar no mundo de trabalho. Em se tratando dos subprojetos de pesquisa do Pibid dos quais participaram, têm-se três egressos da área de Ciências Biológicas, três da Física, dois da Química e quatro da Matemática. Quanto ao tempo de permanência no Pibid, dois egressos de Física (F1 e F3) participaram um ano. Dois egressos das Ciências Biológicas e um da Matemática (B2, B3 e M4) por um período de um ano e meio e três egressos de Matemática, dois de Química, um de Física e um de Ciências Biológicas (B1, F2, M1, M2, M3, Q1, Q2) permaneceram por dois anos ou mais.

O período de atuação do egresso no programa, ao variar entre um a dois anos ou mais, poderia dar alguns indícios como a satisfação dos envolvidos. Nesse sentido, pode-se dizer que ou o programa conseguiu, de fato, segurar os bolsistas de iniciação à docência até o final dos cursos 
de licenciatura, ou ainda que a permanência destes bolsistas no programa por dois anos ou mais, aponta para a necessidade financeira. Explicando, mesmo que o valor da bolsa não seja muito, para o pibidiano é fundamental para a sua sobrevivência no curso superior de licenciatura.

Buscando conhecer se o Pibid contribuiu para que os egressos permanecessem na licenciatura, a pesquisa mostrou que oito bolsistas, sendo dois das Ciências Biológicas, quatro da Matemática e dois da Química afirmaram que sim; quatro afirmaram que não, sendo um das Ciências Biológicas e três da Física. Porém B2, F2, F3, Q1 e M3 não justificaram suas respostas. As justificativas podem se lidas abaixo no quadro:

Quadro 2 - Contribuição do Pibid para permanência no curso de licenciatura

\begin{tabular}{|c|l|}
\hline Egressos & \multicolumn{1}{c|}{ Respostas } \\
\hline B3 & $\begin{array}{l}\text { Sim. O contato direto com a profissão já nos dá uma base para decidir o que } \\
\text { realmente queremos. }\end{array}$ \\
\hline M1 & $\begin{array}{l}\text { Sim. O PIBID teve grande contribuição para permanecer na licenciatura, só } \\
\text { não atuo mais devido melhores oportunidades em outros ramos }\end{array}$ \\
\hline M2 & Sim. Pois é uma área que gosto de atuar \\
\hline M4 & Sim. principalmente na parte financeira \\
\hline Q2 & $\begin{array}{l}\text { Sim, pela questão financeira e pela perspectiva profissional. Ao longo do } \\
\text { curso, várias disciplinas de conhecimento específico me desanimavam por } \\
\text { não ver muito sentido naquelas abordagens. Ao mesmo tempo, fazer parte } \\
\text { do PIBID me trazia tanta felicidade e alegrias, que eu percebia que para } \\
\text { atingir meu objetivo de vida de ser professor, valia a pena continuar na } \\
\text { licenciatura. }\end{array}$ \\
\hline B1 & Não. Essa profissão é difícil viu, já no PIBID estava frustrada! \\
\hline F1 & $\begin{array}{l}\text { Não. Não tinha outra opção na região. O curso de bacharelado só tem em } \\
\text { Goiânia. Mas, foi uma excelente escolha ter continuado na licenciatura. }\end{array}$ \\
\hline
\end{tabular}

Fonte: Guarda (2019, p.100).

Observando-se as justificativas, têm-se aqueles egressos que consideram que o contato com a profissão permitiu decidir a permanência ou não na licenciatura. No caso do egresso da Matemática (M1) o Pibid possibilitou sua permanência na licenciatura, mas não garantiu sua atuação na área, devido às melhores oportunidades que outras áreas poderiam oferecer. Por sua vez, outro da Matemática (M4) alegou sua permanência no curso de licenciatura e destacou a influência do recurso financeiro que o programa disponibilizou. Do mesmo modo, o egresso da Química (Q2) mencionou as contribuições do programa na questão financeira e profissional, além de o Pibid tê-lo levado a refletir e permanecer na licenciatura. Mesmo que o respondente da Física (F1) tenha marcado a opção não, sua justificativa mostra que foi uma boa escolha continuar na licenciatura, então, entende-se que o Pibid assegurou a permanência desse egresso no curso de licenciatura. Em contrapartida, temos os egressos que justificaram a não contribuição do programa para sua permanência na licenciatura, como a respondente das Ciências Biológicas (B1) ao justificar que o Pibid a deixou frustrada.

Com base nas respostas pela maioria dos egressos, pode-se constatar que o Pibid contribuiu para que os licenciandos permanecessem nos cursos de licenciatura, seja por gostarem da docência ou pelo suporte financeiro disponibilizado aos bolsistas.

Os dados se aproximam dos resultados da pesquisa realizada por Moura (2013) sobre as contribuições do Pibid na formação inicial de professores, ou seja, assegura a permanência dos 
estudantes nos cursos de licenciatura, levando-os a concluírem o ensino superior. Essa afirmação embasa ao que o respondente $\mathrm{F} 1$ afirmou de seu interesse pela docência, mesmo que a licenciatura não tenha sido a sua primeira opção.

Por outro lado, é importante destacar que essa percepção não é uníssona, pois em outras realidades, como destaca Lima (2016) ao pesquisar sobre as influências do Pibid de Educação Física em relação aos egressos na escolha da escola como lócus de atuação profissional, este concluiu que os egressos não escolheram a escola como área de atuação. Seus dados revelaram que a maioria preferiu atuar fora da docência, pois a formação desses egressos possibilitava esse deslocamento da área escolar para não escolar. A razão dessa mudança ocorreu pelas más condições de trabalho e a desvalorização da Educação Física escolar, desestimulando os egressos a exercerem a docência.

No que se refere aos egressos questionados da razão de terem escolhido em participar do Pibid, a pesquisa apontou dois grupos, o primeiro a busca pela experiência, em conhecer a área da docência e o cotidiano escolar; e o segundo, pela bolsa ofertada aos participantes. Desta forma, se por um lado um egresso das Ciências Biológicas, Matemática e Química e dois da Física (B1, F1, F2, M3, Q2) fizeram menção à bolsa dando-os a motivação para se interessarem pelo Pibid, por outro lado, dois egressos das Ciências Biológicas, da Matemática e um da Física (B1, B2, F3, M1, M2) citaram a oportunidade de adquirir experiência com o programa; dois egressos da Matemática, um das Ciências Biológicas, Física e Química (B3, F2, M1, M4, Q) alegaram a oportunidade de conhecer a profissão e um egresso da Matemática e outro da Física (M4 e Q2) pela oportunidade de conhecer a área escolar. Importante destacar que dois dos respondentes do curso de Física (F1e F2) optaram pela licenciatura, pois para um faltava o curso na área de bacharelado, e o outro não ter a opção do curso de Engenharia Mecânica.

Considerando a importância da bolsa para continuar ou não no programa, quatro egressos responderam que ficariam no programa caso não tivessem mais bolsa. Em compensação, oito egressos não permaneceriam no Pibid se houvesse o corte do suporte financeiro. Não resta dúvida que a bolsa é fundamental para a adesão do licenciando ao Pibid e a se manter na licenciatura.

O incentivo financeiro é relevante conforme dados apresentados também por Gatti et al (2014) ao trazerem a contribuição do programa para os participantes (coordenador de área, supervisor e licenciando bolsista). Segundo as autoras destacaram, a bolsa é um dos quesitos para permanência do estudante na universidade.

Quanto à contribuição das atividades desenvolvidas durante o Pibid para a formação inicial dos egressos, onze justificaram afirmativamente, conforme o quadro 3 a seguir. Somente o egresso da Física (F2) alegou que o Pibid não contribuiu para a sua formação, pela falta de organização do programa no subprojeto que participou. Por outro lado, para os demais, o Pibid possibilitou a aprendizagem na prática docente, novas experiências, conhecer e desenvolver novas metodologias, melhorar a escrita e a oralidade, vivenciar o cotidiano escolar.

Quadro 3 - Contribuição das atividades no Pibid na formação inicial do egresso da UFG/REJ

\begin{tabular}{|c|l|}
\hline Egressos & \multicolumn{1}{c|}{ Respostas } \\
\hline B1 & $\begin{array}{l}\text { Sim. Aprendi muito com a experiência dos professores, tanto na forma de didática ao } \\
\text { ministrar as aulas quanto para os desafios da profissão. }\end{array}$ \\
\hline B2 & Sim. Adquiri experiência e gosto pela docência. \\
\hline B3 & Sim. Pude perceber que a prática facilita a aprendizagem \\
\hline
\end{tabular}




\begin{tabular}{|c|l|}
\hline F1 & $\begin{array}{l}\text { Sim. Foi um momento interessante. Tive contato com os alunos, ajudei em suas dú- } \\
\text { vidas, participei da realidade do ensino de Física nas escolas e vi o grande desafio em } \\
\text { transmitir o conhecimento desta área. Isso me motivou grandemente em continuar na } \\
\text { licenciatura e a procurar formas de tentar modificar um pouco desta realidade. }\end{array}$ \\
\hline F3 & Sim. Observar a diferença entre teoria e prática, que estão muito distantes. \\
\hline M1 & Sim. Desenvolvi projetos e ajudei alunos com dificuldade em matemática \\
\hline M2 & Sim. Na troca de experiência e proporcionar a relação professor/aluno \\
\hline M3 & Sim. Me ajudou a vivenciar a sala de aula \\
\hline M4 & $\begin{array}{l}\text { Sim. Foi o que mais contribuiu na minha formação acadêmica e que contribuiu para } \\
\text { que hoje estivesse trabalhando na área da educação. }\end{array}$ \\
\hline Q2 & $\begin{array}{l}\text { Sim. Através do PIBID pude melhorar meus hábitos de estudo, reconhecer os conteú- } \\
\text { dos que os alunos apresentam maiores dificuldades de aprendizagem, ter contato com } \\
\text { o desenvolvimento e avaliação de metodologias de ensino diversificadas (experimen- } \\
\text { tação, temas geradores), construir projetos de pesquisa, melhorar a argumentação oral } \\
\text { e escrita. }\end{array}$ \\
\hline F2 & $\begin{array}{l}\text { Não. Quando participei do PIBID era muito mal administrado por parte do coordena- } \\
\text { dor responsável e pelo professor da escola. }\end{array}$ \\
\hline
\end{tabular}

Fonte: Guarda (2019, p. 105).

Araujo et al (2017) ao pesquisarem os bolsistas da Universidade Federal de Mato Grosso do Sul, buscando identificar as influências do Pibid na formação inicial e na prática docente na educação básica, identificaram que para estes bolsistas o Pibid contribuiu para a aprendizagem, experiência, prática docente, formação profissional e conhecimento. Com isso as autoras afirmam que

experienciar a futura profissão, ampliar conhecimento acadêmico, aprender na diversidade são os pilares do PIBID por propiciar aos acadêmicos dos cursos de licenciatura a vivência nos espaços escolares, lócus do trabalho docente. Essa vivência é mais do que a extensão da universidade, significa aprender e aprender na escola e com a escola, com professores e alunos, de modo singular e capaz de fortalecer e erigir a instituição escolar com espaço de formação (ARAUJO et al, 2017, p. 52, grifo das autoras).

Se por um lado, para as autoras a oportunidade de vivenciar o ambiente escolar é importante para a formação inicial, pois o bolsista aprende na escola e com a escola, por outro, não se pode esquecer da formação no ambiente científico. Ou seja, se recusa aqui a epistemologia da prática. Tal perspectiva ficou evidente quando se analisou na pesquisa os subprojetos dos cursos, pois estes estão de acordo com os princípios pedagógicos do Pibid que, segundo destacado do Relatório de Gestão da DEB (2009-2013a), são contemporâneos e claros, segundo a perspectiva de Nóvoa. Percebeu-se que os subprojetos deram ênfase para uma formação por competências e priorizaram a prática como elemento principal da formação, dando indícios que o programa, nesses cursos, sustentou-se por autores que defendem a epistemologia da prática (GUARDA, 2019).

Nesse sentido, Duarte (2010) contribui para a reflexão sobre a formação de professores, anunciando que a pedagogia do aprender a aprender está voltada para o conhecimento tácito, ou seja, o conhecimento do cotidiano, ou da prática da experiência. Nessa vertente, nega-se e desvaloriza-se a transmissão do conhecimento sistematizado, pois é o aluno que direciona a aula conforme seus interesses e suas necessidades. 
O conhecimento decisivo para as decisões que o professor toma em sua atividade profissional não é aquele proveniente dos livros e das teorias, mas o conhecimento tácito que se forma na ação, no pensamento que acompanha a ação e no pensamento sobre o pensamento que acompanha a ação (DUARTE, 2010, p. 42).

O conhecimento, proveniente das teorias, deixa de ser decisivo no trabalho do professor e o conhecimento prático torna-se elemento central na atividade profissional. Nesse viés, o que importa é formar alunos criativos para melhor adaptar-se ao sistema capitalista, sem criticar a realidade e buscar meios para uma transformação social.

Defende-se aqui que a universidade ainda seja o espaço importante de formação docente, pois é no ambiente universitário que se desenvolve o conhecimento científico, essencial para a prática docente. A formação defendida é aquela voltada para a práxis, uma educação que forma um cidadão consciente, capaz de transformar criticamente a sociedade voltada aos interesses capitalistas e não adaptar-se ao sistema capitalista de produção. Nesse contexto, a educação ultrapassa o conhecimento do senso comum e se apropria do conhecimento científico, desvelando a aparência que o sistema capitalista impõe à educação para se chegar à essência do processo de formação humana.

Assim, torna-se necessária uma formação alicerçada em uma perspectiva crítica, por meio de um debate histórico, político, sociológico e filosófico para a compreensão da realidade.

Considerando a contribuição do Pibid na formação dos egressos, nota-se que o programa favoreceu para que todos conhecessem a escola e o trabalho desenvolvido no seu interior, despertando ou não para que escolhessem a docência como área de atuação profissional. Dez egressos escolheram a opção de que o programa auxilia na relação teoria e prática e a falar em público. Cinco egressos acreditam no auxílio do programa em relação ao planejamento de atividades pedagógicas e oito egressos acreditam que o programa beneficiou a produzir o artigo científico, instigando para a investigação. O gráfico abaixo sistematiza as respostas.

Gráfico 1 - Contribuição do Pibid na formação dos egressos da UFG/REJ

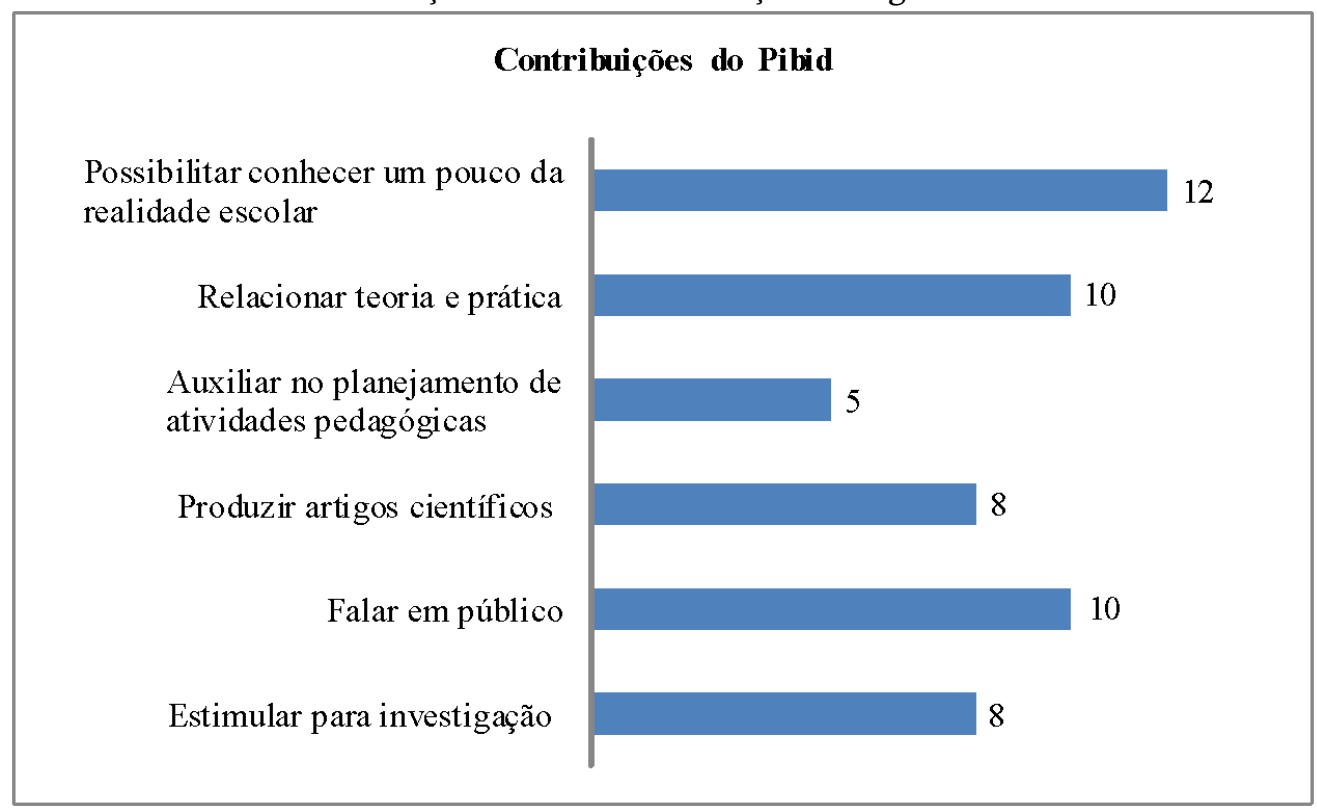

Fonte: Guarda, (2019, p. 114). 
E, por fim, respondendo a questão se os egressos dos cursos de licenciatura em Biologia, Física, Química e Matemática, da Universidade Federal de Goiás, Regional Jataí, que participaram do Pibid, estão atuando na educação básica após a conclusão do curso, pode-se afirmar que dos 12 respondentes, cinco exercem a docência na educação básica. Sendo três na rede pública de ensino, área de Matemática e Química; dois na rede de ensino privada, também na área de Matemática e Química. Quatro egressos não trabalham na educação básica, e como justificativas têm-se que os dois da área de Física optaram pela pós-graduação, os outros dois, da Matemática e Ciências Biológicas não justificaram. Os outros três egressos não responderam a pergunta.

Os dados da pesquisa apontaram que o investimento do Pibid para a permanência dos licenciandos nos cursos, se por um lado contribuiu para a formação de seus participantes nas áreas especificas de diferentes maneiras, por outro não conseguiu que todos continuassem na docência após a conclusão da licenciatura. A não atuação na educação básica posteriormente à conclusão da licenciatura deve ser analisada de forma mais ampla.

Relatos de pesquisas revelaram que o Pibid teve seus resultados positivos, como Martins (2013), Silva (2014), Barros (2016), Sombra (2016), Gehring (2016) Gonçalves (2016) e Demari (2017) que em comum afirmaram as contribuições como, por exemplo, a relação entre teoria e prática, universidade e escola, influenciou na prática docente, fez com que alguns egressos permanecessem na docência e ainda oportunizou o conhecimento da realidade escolar.

Mas é preciso considerar como lembra Freitas (2007), se o país está preocupado em ter bons professores é preciso melhorar as condições de trabalho e salário dos docentes, uma vez que, não é suficiente somente criar novas instituições de ensino e nem tornar a profissão mais atraente.

Ainda é preciso refletir sobre as fragilidades do programa como, por exemplo, não ser para todos os que estão na licenciatura, privilegiando apenas aqueles que são selecionados por mérito de desempenho e assim deixando de fora os que mais têm necessidades e dificuldades.

A pesquisa junto aos egressos do Pibid na UFG/Regional Jataí buscou contribuir também para uma discussão mais ampla sobre as políticas públicas educacionais e a formação inicial de professores no âmbito das instituições de ensino superior e desta forma identificar as possíveis contribuições, mas também as contradições do programa em âmbito nacional.

Se por um lado houve o aumento das áreas de licenciaturas contempladas a participarem do programa desde 2009, o aumento do número de bolsas e as contribuições do na formação inicial dos egressos, especialmente no que se refere à experiência docente, possibilidade de conhecer ambiente escolar e seus desafios, além de desenvolver para a pesquisa, por outro se identificou as contradições nos últimos anos, quando o Pibid passou a contemplar também as instituições de ensino privado, estimulando o setor privado e o não investimento no setor público, ao transferir recursos públicos para o privado. Isso fez com que o Pibid mudasse seu foco, deixando de ampliar os investimentos na esfera pública. Outra contradição foram os cortes nos recursos financeiros iniciados em 2015, justamente quando o atual Plano Nacional de Educação (20142024), Lei $n^{\circ} 13.005$, de 25 de junho de 2014, incorpora o Pibid apresentando-o como uma das estratégias para alcançar o objetivo da meta 15: "ampliar o programa permanente de iniciação à docência a estudantes matriculados em cursos de licenciatura, a fim de aprimorar a formação de profissionais para atuar no magistério da educação básica" (BRASIL, 2014, p. 32). 
Vieira (2017), ao pesquisar sobre o Pibid, com ênfase na política e gestão educacional, concluiu que o programa, mesmo com as possíveis descontinuidades, continua caminhando para ser uma Política de Estado. A autora afirma que "para se tornar seguramente parte de uma política de Estado, o Pibid precisa de uma sustentação social, institucional, política e financeira" (p. 104). Esse apoio de diferentes áreas é importante para que o programa crie forças no campo na educação. Mas para que isso ocorra também é preciso que ele atenda a todos os licenciandos e não apenas a uma pequena parcela deles que concorrem à vaga provocando ao que Freitas (2007) afirma de uma desigualdade educacional.

\section{Considerações Finais}

Este artigo se propôs a analisar de forma crítica o Pibid na formação inicial de licenciandos em Ciências Biológicas, Física, Matemática e Química da UFG/REJ e a inserção dos mesmos na educação básica, após a conclusão do curso. Para isso se apresentou os dados da pesquisa empírica realizada no programa de pós-graduação Mestrado em Educação, que contou com a participação de 12 egressos dos cursos em tela.

Considera-se que o investimento do Pibid, via bolsas para a iniciação a docência, foi fundamental para a permanência dos licenciandos nos cursos, pois o suporte financeiro exerceu influência positiva para que os respondentes continuassem seus estudos.

Da mesma forma, as atividades desenvolvidas e as vivências no ambiente escolar colaboraram para ampliar a experiência, inserção na pesquisa e o desejo ou não de continuar na docência após a conclusão do curso. Os resultados evidenciaram as contribuições do Pibid na formação inicial destes egressos, oportunizando conhecer o contexto escolar, as diversas metodologias para as aulas, melhorar a escrita e a oralidade, ou seja, estar nesse ambiente escolar foi um elemento formativo importante.

Outra questão evidenciada foi a relação teoria e prática. Como a ênfase nos subprojetos privilegiou a epistemologia da prática em detrimento da práxis, a formação inicial desses licenciados pautou-se mais na pedagogia do aprender a aprender, o que pode indicar uma formação mais técnica em detrimento de uma formação crítica, voltada para a cidadania.

Quanto à atuação na educação básica, após a conclusão do curso, apenas cinco egressos de fato estão na docência, tanto na escola pública quanto na privada. Salienta-se que existem diversos fatores que podem pesar para que esses egressos não atuem na docência como, por exemplo, a busca pela pós-graduação como afirmaram dois egressos. Mas a falta de oportunidade de vaga disponível na rede privada, a ausência de concurso público e o desestímulo devido à desvalorização do magistério na educação básica e as más condições de trabalho são fatores que precisam ser pesados.

O programa ao longo de sua existência apresentou contradições. Se por um lado houve abertura para mais licenciaturas aderirem ao Pibid a partir das primeiras experiências exitosas, por outro os investimentos também se estenderam as instituições privadas de ensino superior, reduzindo assim as verbas para os cursos de licenciatura presentes no ensino público seja federal, estadual ou municipal.

O Pibid se apresentou como uma possibilidade para uma política de estado ao estar contemplado em uma das estratégias da meta 15 do Plano Nacional de Educação (2014-2024), mas com a redução dos investimentos do governo federal no âmbito da educação pública congelando 
os gastos por 20 anos, pode levar o programa a se definhar e a perder o seu propósito de contribuir para a formação inicial de professores.

\title{
PIBID IN INITIAL FORMATION AND INSERTING TEACHING IN BASIC EDUCATION
}

\begin{abstract}
As a result of research supported by CAPES, this article problematized the Institutional Program of Initiation to Teaching Scholarship (Pibid) of undergraduate courses in Biology, Physics, Mathematics and Chemistry at the Federal University of Goiás, Regional Jataí. The objective was to understand the implementation of the program contributed to the permanence of the students in the degree courses and in the initial formation, leading them, later, to act in basic education. The qualitative investigation was based on a questionnaire sent to 97 egresses of undergraduate courses through the Google-Drive system, with critical content analysis in the contributions of Duarte (2010), Freitas (2007) e Vieira (2017). Technical rationality was evident in the subprojects developed to the detriment of the praxis. Of the egresses, twelve stated that the program contributed to the initial training allowing them to know the school reality, to identify their own or not by the chosen degree course; the scholarships were essential for the permanence in the courses, but only five of them are working in basic education.
\end{abstract}

KEYWORDS: Initial teacher training. Institutional Program of Initiation to Teaching Scholarship. Basic education teaching.

\section{REFERÊNCIAS}

ARAUJO. Carla B. Zandavalli M. et al. As influências do Pibid sobre a formação inicial e continuada de professores: o olhar dos bolsistas de iniciação à docência da UFMS. In: URT. Sônia da Cunha. Políticas educacionais e formação: produção, projetos e ações em Educação. Campo Grande: Editora Oeste, 2017, p. 31-73.

BARROS, Alinic Vieira de. Contribuições do programa institucional de bolsas de iniciação à docência para a formação inicial dos egressos das licenciaturas da Universidade Federal do ABC. Dissertação de Mestrado. Programa de Pós-Graduação em Ensino e História das Ciências e da Matemática Instituição de Ensino da Universidade Federal do ABC, São Paulo. 2016. Disponível em: https://sucupira.capes.gov.br/ sucupira/public/consultas/coleta/trabalhoConclusao/viewTrabalhoConclusao.jsf?popup=true\&id trabalho=3787810 Acesso em: 24/6/ 2017.

BASSO, I. S. Significado e sentido do trabalho docente. Cadernos Cedes, Campinas, ano XIX, n.44, p.19-32, abril 1998. Disponível em: https://www.scielo.br/scielo.php?pid=S010132621998000100003\&script $=$ sci abstract\&tlng=pt Acesso em: 21/6/2020.

BRASIL. Coordenação de Aperfeiçoamento de Pessoal de Nível Superior - Capes. Diretoria de formação de professores da educação básica - DEB. Relatório de Gestão 2009-2013. Brasília, DF, 328 p, $2013 a$. Disponível em: http://www.capes.gov.br/images/stories/download/bolsas/2562014-relatrorio-DEB2013-web.pdf. Acesso em: 5/4/ 2018.

BRASIL. Decreto $n^{\circ}$ 6.755, de 29 de janeiro de 2009. Institui a Política Nacional de Formação de Profissionais do Magistério da Educação Básica, disciplina a atuação da Coordenação de Aperfeiçoamento de Pessoal de Nível Superior - Capes no fomento a programas de formação inicial e continuada, e dá outras providências. Brasília, DF, 2009. Disponível em: https://www.capes.gov.br/images/stories/ download/legislacao/Decreto-6755-2009.pdf. Acesso em: 12/12/ 2017.

BRASIL. Lei no 9.394, de 20 de dezembro de 1996. Estabelece as Diretrizes e Bases da Educação Nacional. Diário Oficial da União, Brasília, DF, 23 dez. 1996.

BRASIL. Lei ${ }^{\circ} 13.005$, de 25 de junho de 2014. Aprova o Plano Nacional de Educação-PNE e dá outras providências. Brasília. 2014b. Disponível em: http://www.planalto.gov.br/ccivil 03/ ato20112014/2014/lei/113005.htm Acesso em: 13/2/ 2018.

BRASIL. Lei ${ }^{\circ}$ 12.796, de 4 de abril de 2013. Altera a Lei 9.394, de 20 de dezembro de 1996, que estabelece as diretrizes e bases da educação nacional, para dispor sobre a formação dos profissionais 
da educação e dar outras providências. 2013b. Disponível em: http://www.planalto.gov.br/ccivil 03/ ato2011-2014/2013/lei/112796.htm Acesso em: 14/12/ 2017.

BRASIL. Lei ${ }^{\circ} 13.635$ de 20 de março de 2018. Cria a Universidade Federal de Jataí, por desmembramento da Universidade Federal de Goiás. 2018b. Disponível em: http://www.planalto.gov.br/ccivil 03/ ato2015-2018/2018/Lei/L13635.htm Acesso em: 20/6/ 2018.

BRASIL. O Plano de Desenvolvimento da Educação: razões, princípios e programas. Brasília: MEC, 2007. Disponível em: http://portal.inep.gov.br/documents/186968/485287/O+Plano+de+Desenvolvi mento + da + Educa $\% \mathrm{C} 3 \% \mathrm{~A} 7 \% \mathrm{C} 3 \% \mathrm{~A} 3 \mathrm{o}+$ raz $\% \mathrm{C} 3 \% \mathrm{~B} 5 \mathrm{es} \% 2 \mathrm{C}+$ princ $\% \mathrm{C} 3 \% \mathrm{ADpios}+\mathrm{e}+$ programas $/ 3 \mathrm{c} 6 \mathrm{a}$ db19-4c2e-4c60-9ccb-3b476bed9358?version=1.6 Acesso em: 20/5/2020.

DEMARI, Jennifer. A formação docente no Pibid/Química da UFRGS na perspectiva dos egressos do Programa. Dissertação de Mestrado. Programa de Pós-Graduação em Educação em Ciências Química da Vida e Saúde da Universidade Federal do Rio Grande do Sul. Porto Alegre. 2017. Disponível em: https:// sucupira.capes.gov.br/sucupira/public/consultas/coleta/trabalhoConclusao/viewTrabalhoConclusao. jsf?popup=true\&id trabalho=5011056 Acesso em: 28/6/ 2017.

DUARTE, Newton. O debate contemporâneo das teorias pedagógicas. In: MARTINS, Lígia Márcia; NEWTON, Duarte (Orgs.). Formação de professores: limites contemporâneos e alternativas necessárias. São Paulo: Editora UNESP, 2010, p. 33-51.

FREITAS, Helena Costa Lopes de. A (nova) política de formação de professores: a prioridade postergada. Educação e Sociedade, Campinas, v. 28, n. 100, p. 1203-1230, 2007. Disponível em: http:// www.scielo.br/pdf/es/v28n100/a2628100 Acesso em: 15/4/ 2018.

GATTI, Bernadete Angelina et al. Um estudo avaliativo do Programa Institucional de Bolsa de Iniciação à Docência (Pibid). São Paulo: FCC/SEP, v. 41, 2014. Disponível em: https://www.capes.gov.br/images/ stories/download/bolsas/24112014-pibid-arquivoAnexado .pdf Acesso em: 10/1/ 2018.

GEHRING, Fernanda Maria Muller. Formação inicial de professores de Língua Portuguesa: retratos e reflexos do Pibid. 2016. 227 f. Dissertação de Mestrado. Programa de Pós-Graduação em Letras da Universidade Estadual do Oeste do Paraná, Cascavel, 2016. Disponível em: https://sucupira.capes.gov.br/ sucupira/public/consultas/coleta/trabalhoConclusao/viewTrabalhoConclusao.jsf?popup=true\&id trabalho $=4156560$ Acesso em: 24/6/ 2018.

GONÇALVES, Glaucia Signorelli de Queiroz. Inserção profissional de egressos do Pibid: desafios e aprendizagens no inicio da docência. Tese de Doutorado. Programa de Pós-Graduação em Educação da Pontifícia Universidade Católica de São Paulo, São Paulo, 2016. Disponível em: https://sucupira. capes.gov.br/sucupira/public/consultas/coleta/trabalhoConclusao/viewTrabalhoConclusao. jsf?popup=true\&id trabalho=3745134 Acesso em: 24/6/ 2017.

GUARDA, Juliana Alves da. Programa institucional de bolsa de iniciação à docência: contribuições para a formação inicial e para a inserção na docência da educação básica. Dissertação de Mestrado. Programa de Pós-Graduação em Educação da Universidade Federal de Goiás, Jataí, 2019. Disponível em: http:// repositorio.bc.ufg.br/tede/bitstream/tede/9481/5/Disserta\%c3\%a7\%c3\%a3o\%20-\%20Juliana\%20 Alves\%20da\%20Guarda\%20-\%202019.pdf Acesso: 20/8/ 2019.

LIMA, Sabrina Aparecida de. A atratividade da carreira docente: uma análise na perspectiva de exbolsistas do Pibid do curso de Educação Física. Dissertação de Mestrado. Programa de Pós-Graduação em Educação da Universidade Federal de Viçosa, Viçosa (MG), 2016. Disponível em: https:// sucupira.capes.gov.br/sucupira/public/consultas/coleta/trabalhoConclusao/viewTrabalhoConclusao. jsf?popup=true\&id trabalho=4451586 Acesso em: 24/6/ 2017.

MARTINS, Maria Márcia Melo de Castro. Saberes pedagógicos e o desenvolvimento de metodologias de ensino de Biologia: o Pibid como elemento de construção. Dissertação de Mestrado Profissional. Programa de Pós-Graduação em Educação Profissional: Ensino de Ciências e Matemática da Universidade Federal do Ceará, Ceará. 2013. Disponível em: https://sucupira.capes.gov.br/sucupira/public/consultas/ coleta/trabalhoConclusao/viewTrabalhoConclusao.jsf?popup=true\&id trabalho=153459 Acesso em: 28/6/ 2017. 
MOURA, Eduardo Junio Santos. Iniciação à docência como política de formação de professores. Dissertação de Mestrado. Programa de Pós-Graduação em Educação da Universidade de Brasília, Brasília, 2013. Disponível em: http://repositorio.unb.br/bitstream/10482/15025/1/2013 EduardoJunioSantosMoura.pdf. Acesso em: 28/6/ 2017.

SILVA, Danielli Ferreira. Processo de iniciação à docência de professores de matemática: olhares de egressos do Pibid/UFSCar. Dissertação de Mestrado. Programa de Pós-Graduação em Educação da Universidade Federal de São Carlos, São Carlos. 2014. Disponível em: https://sucupira.capes.gov.br/ sucupira/public/consultas/coleta/trabalhoConclusao/viewTrabalhoConclusao.jsf?popup=true\&id trabalho=1420563 Acesso em: 28/6/ 2017.

SOMBRA, Cintia Goncalves. Egressos do Pibid/UECE dos subprojetos de Ciências Biológicas, Física e Química: onde atuam e o que pensam sobre a permanência na docência? Dissertação de Mestrado. Programa de Pós-Graduação em Educação da Universidade Estadual do Ceará, Fortaleza, 2016. Disponível em: https://sucupira.capes.gov.br/sucupira/public/consultas/coleta/trabalhoConclusao/ viewTrabalhoConclusao.jsf?popup=true\&id trabalho=4764206 Acesso em: 24/6/ 2017.

VIEIRA, Karen Eich. Programa institucional de bolsa de iniciação à docência (Pibid) na UFGD/ MS: recorrências e solicitações da realidade. Dissertação de Mestrado. Programa de Pós-Graduação em Educação da Universidade Federal da Grande Dourados, Dourados, 2017. Disponível em: http:// files.ufgd.edu.br/arquivos/arquivos/78/MESTRADO-DOUTORADO-EDUCACAO/KAREN\%20 EICH\%20VIEIRA.pdf Acesso em: 2/7/ 2018. 